\title{
Acquisition and generalization of appetitive responding in obese and healthy weight females
}

Citation for published version (APA):

van den Akker, K., Schyns, G., Breuer, S., van den Broek, M., \& Jansen, A. (2019). Acquisition and generalization of appetitive responding in obese and healthy weight females. Behaviour Research and Therapy, 123, [103500]. https://doi.org/10.1016/j.brat.2019.103500

Document status and date:

Published: 01/12/2019

DOI:

10.1016/j.brat.2019.103500

Document Version:

Publisher's PDF, also known as Version of record

Document license:

Taverne

\section{Please check the document version of this publication:}

- A submitted manuscript is the version of the article upon submission and before peer-review. There can be important differences between the submitted version and the official published version of record.

People interested in the research are advised to contact the author for the final version of the publication, or visit the DOI to the publisher's website.

- The final author version and the galley proof are versions of the publication after peer review.

- The final published version features the final layout of the paper including the volume, issue and page numbers.

Link to publication

\footnotetext{
General rights rights.

- You may freely distribute the URL identifying the publication in the public portal. please follow below link for the End User Agreement:

www.umlib.nl/taverne-license

Take down policy

If you believe that this document breaches copyright please contact us at:

repository@maastrichtuniversity.nl

providing details and we will investigate your claim.
}

Copyright and moral rights for the publications made accessible in the public portal are retained by the authors and/or other copyright owners and it is a condition of accessing publications that users recognise and abide by the legal requirements associated with these

- Users may download and print one copy of any publication from the public portal for the purpose of private study or research.

- You may not further distribute the material or use it for any profit-making activity or commercial gain

If the publication is distributed under the terms of Article $25 \mathrm{fa}$ of the Dutch Copyright Act, indicated by the "Taverne" license above, 


\title{
Acquisition and generalization of appetitive responding in obese and healthy weight females
}

\author{
Karolien van den Akker ${ }^{\mathrm{a}, \mathrm{b}, *}$, Ghislaine Schyns ${ }^{\mathrm{a}}$, Sabrina Breuer ${ }^{\mathrm{a}}$, Myrr van den Broek ${ }^{\mathrm{a}}$, \\ Anita Jansen $^{\mathrm{a}}$ \\ ${ }^{a}$ Faculty of Psychology and Neuroscience, Department of Clinical Psychological Science, Maastricht University, P.O. Box 616, 6200, MD, Maastricht, the Netherlands \\ ${ }^{\mathrm{b}}$ CentERdata, Tilburg University, Intermezzo Building, Professor de Moorplein 524-525, P.O. Box 90153, 5037, DR, Tilburg, the Netherlands
}

\section{A R T I C L E I N F O}

\section{Keywords:}

Obesity

Appetitive conditioning

Acquisition

Generalization

Anxiety

\begin{abstract}
A B S T R A C T
Findings of a few recent studies suggest that obesity is characterized by deficits in appetitive learning about food cues. This could point towards an increased tendency in obese individuals to overgeneralize appetitive responding to stimuli that resemble the conditioned food cue - possibly explaining frequent eating desires and overeating in obesity. The current study aimed to investigate whether obese individuals 1) indeed exhibit appetitive learning deficits and 2) show overgeneralization of conditioned appetitive responses. Obese and matched healthy-weight females $(N=85)$ completed a differential appetitive conditioning task using food as rewards. First, appetitive responding to a novel stimulus was learned (acquisition phase), after which stimuli with varying resemblance to the food-associated stimulus were presented (generalization phase). Cue-elicited eating expectancies, eating desires, stimulus evaluations, and actual food intake were examined. Results indicated successful acquisition of appetitive responding across all outcome measures. The acquired responses also generalized, indicating that generalization can function as an additional mechanism by which learned food cues can promote food consumption. The data further suggested that overweight and obesity are not characterized by appetitive learning deficits nor by overgeneralization, but that a subgroup of obese individuals (those high in trait anxiety) may be more prone to overgeneralization of appetitive responding.
\end{abstract}

\section{Introduction}

Obesity prevalence remains high, with over $36 \%$ of U.S adults currently being obese (Ogden et al., 2016). It is thought that our 'obesogenic' environment - which offers an abundance of tasty, cheap, and high-calorie food - is the main driver of overconsumption and weight gain (Swinburn, Egger, \& Raza, 1999). Specifically, food-associated cues (e.g., the smell of freshly baked pizza, the sight of one's favourite snack bar, etc) within this environment elicit 'food cue reactivity' such as heightened eating desires or cravings, and stimulate (over)eating (Boswell \& Kober, 2016; Jansen, Schyns, Bongers, \& van den Akker, 2016; Nederkoorn, Smulders, \& Jansen, 2000). Yet, not everybody becomes obese in this environment, suggesting the presence of some underlying characteristics in obese individuals that contribute to (food cue-elicited) overeating and weight gain.

Learning models of food cue reactivity propose that food cues are conditioned stimuli (CSs) that have once become associated with intake (unconditioned stimulus or US) through repeated CS - US pairings, and as a consequence, elicit conditioned appetitive responses (CRs, food cue reactivity) (Bouton, 2011; Jansen, 1998; Jansen, Schyns, Bongers, \& Akker, 2016). In line with this idea, studies have shown that after repeated pairings between an arbitrary stimulus (e.g., a geometric shape; $\mathrm{CS}+$ ) and food intake (e.g., eating a piece of chocolate), this stimulus elicits conditioned responses including increased eating desires, eating expectancies, more positive evaluations, and physiological and neural activity, compared with a stimulus never associated with eating (CS -) (Blechert, Testa, Georgii, Klimesch, \& Wilhelm, 2016; van den Akker, Jansen, Frentz, \& Havermans, 2013; van den Akker, Schyns, \& Jansen, 2018; Van Gucht, Vansteenwegen, Van den Bergh, \& Beckers, 2008; Wardle, Lopez-Gamundi, \& Flagel, 2018).

Might inter-individual differences in appetitive learning about food cues account for individual differences in overeating and weight? Recent studies have begun to examine this question by comparing overweight/obese and healthy weight individuals in the learning (acquisition) of appetitive responses to a food-associated CS + vs. a CS - . Interestingly, some studies have reported evidence for worse appetitive

\footnotetext{
${ }^{*}$ Corresponding author. Faculty of Psychology and Neuroscience, Department of Clinical Psychological Science, Maastricht University, P.O. Box 616, 6200, MD, Maastricht, the Netherlands.

E-mail address: karolien.vdnakker@uvt.nl (K. van den Akker).
} 
learning in overweight/obese individuals, as reflected by a reduced discriminative (CS + vs. CS - ) learning of US (eating) expectancies, US (eating) desires, and CS evaluations/preferences (van den Akker, Schyns, \& Jansen, 2017; Coppin, Nolan-Poupart, Jones-Gotman, \& Small, 2014; Zhang, Manson, Schiller, \& Levy, 2014; see also; Kube et al., 2017). Of note, this finding has not been consistently replicated, with data of some studies suggesting a stronger acquisition in overweight/obese individuals (Meemken, Kube, Wickner, \& Horstmann, 2018; Meyer, Risbrough, Liang, \& Boutelle, 2015).

Findings suggesting that obesity is associated with a discriminative learning deficit are counterintuitive, and raise the question how such a deficit might be causally linked to overeating. One intriguing possibility is that reduced discrimination learning translates to overgeneralization (van den Akker et al., 2017). Overgeneralization occurs when one generalizes old experiences to too many new situations (Hermans, Baeyens, \& Vervliet, 2013). For example, an individual who usually eats crisps (US) in the evening while watching television in his or her living room (CS) might learn that this specific situation predicts crisp eating resulting in reactivity to this specific context. In contrast, overgeneralization could result in reactivity to a wider range of stimuli perceptually or conceptually related to the original CS - such as to other people's living rooms, to other 'relaxing' contexts such as a holiday, or to 'evening time' in general. A person who overgeneralizes will thus have many reactivity-eliciting stimuli in his or her environment, promoting frequent food desires and (over)eating - essentially, the environment is more 'obesogenic' for individuals who overgeneralize than for individuals who do not overgeneralize. Such overgeneralization in obesity is in line with the more frequently experienced food cravings in obese individuals compared to healthy weight people (Chao, Grilo, White, \& Sinha, 2014). Further, the discriminative learning deficits in obesity reported in prior studies might point towards overgeneralization since a reduced ability to distinguish predictive and nonpredictive cues can be considered a central characteristic of overgeneralization (Hermans et al., 2013). This idea is supported by the finding that the reduced discriminative learning between a CS + and a $\mathrm{CS}-$ in previous studies was (partially) driven by increased responding to the $\mathrm{CS}-$, which can be a consequence of overgeneralization from the CS + to the CS - (van den Akker et al., 2017; Zhang et al., 2014). To date, no study has directly examined whether obese and healthy weight individuals show differences in generalization. ${ }^{1}$

In addition to weight status, other individual characteristics may exist that are associated with worse acquisition and greater generalization. For example, some fear conditioning studies have found trait anxiety (a tendency to experience anxiety/negative affect in general) to be related to deficient fear acquisition and overgeneralization of fear (Gazendam, Kamphuis, \& Kindt, 2013; Haddad, Pritchett, Lissek, \& Lau, 2012; Lonsdorf \& Merz, 2017; Wong \& Lovibond, 2018), and some evidence suggests that similar relationships might exist for state anxiety (one's current anxiety/negative affect level) (Kuhn, Mertens, \& Lonsdorf, 2016; Vriends et al., 2011). Trait and state anxiety could potentially moderate acquisition and generalization of appetitive responses as well, if they are associated with a more general (rather than fear-specific) predisposition to reduced acquisition/increased generalization (Eaton, Rodriguez-Seijas, Carragher, \& Krueger, 2015; Laufer, Israeli, \& Paz, 2016). This might also be in line with the frequently seen co-morbidities between anxiety disorders and obesity (Gariepy, Nitka, \& Schmitz, 2010).

The main aims of this study are to test whether obesity is characterized by 1) a discriminative appetitive learning deficit, and 2) overgeneralization of learned appetitive responding. To this end, obese and healthy weight individuals are compared on a differential

\footnotetext{
${ }^{1}$ Thus, in the current study, generalization is conceptualized as increased responding to stimuli that resemble the original $\mathrm{CS}+$. Of note, responding may also spread to irrelevant stimuli (Lissek \& van Meurs, 2015).
}

appetitive conditioning task including an acquisition and generalization phase. As secondary aims, it is examined whether inter-individual differences in acquisition and generalization patterns are associated with (1) the frequency in which eating desires are experienced in daily life (as a possible real-life index of generalized appetitive responding) and (2) the level of trait and state anxiety. It is hypothesized that obese vs. healthy weight individuals will show reduced differential learning as well as greater generalization across the outcome measures (US expectancies, US desires, CS evaluations, and actual cue-elicited food intake). Further, it is expected that higher reported desire frequencies and greater levels of trait and state anxiety will be related to a worse acquisition and more generalization.

\section{Methods and materials}

\subsection{Participants}

Eighty-five women took part in the study (obese [OB]: $n=45$; healthy weight $[\mathrm{HW}]: n=40$ ). An a priori sample size analysis using differences in post-acquisition differential (CS + vs CS-) eating desires between overweight and healthy weight females (Cohen's $d=0.62$ ) obtained in a prior study (van den Akker et al., 2017) ${ }^{2}$ showed that 84 participants would be needed (alpha $=0.05$, power $=0.80$ ). The two groups were recruited from the community and matched on age and education level. Participants were screened on inclusion and exclusion criteria during a phone interview. Inclusion criteria were: age 18-60, $\mathrm{BMI}>30(\mathrm{OB})$ or 18.5-24 (HW) and indicating a liking for one of the USs. Exclusion criteria were: self-reported pregnancy, prior bariatric surgery, current severe physical illness, current use of psychotropic medication, and current or prior ( $<5$ years) diagnosis of psychotic disorder. The HW group was additionally required to report no current or recent $(<5$ years) diagnosed mental disorder and no recent considerable weight loss ( $>5 \mathrm{~kg}$ over 6 months). Seven participants in the OB group reported one or more current or prior $(<5$ years) diagnosed co-morbid conditions, including eating disorders $(n=2)$, drug abuse $(n=1)$, anxiety disorders $(n=5)$, depressive disorders $(n=5)$, and personality disorders $(n=2)$. All participants were instructed to have a small meal (e.g., a sandwich) $2 \mathrm{~h}$ prior to the start of the study. Participants received a monetary compensation for participation. The study was approved by the local ethical committee. For participant characteristics, see Table 1.

\subsection{Overview of the study}

Participants completed a differential appetitive conditioning paradigm including two phases: acquisition and generalization. During acquisition, presentation of a (e.g., large) circle $(\mathrm{CS}+$ ) was repeatedly followed by US intake. Another (e.g., small) circle (CS-) was never followed by food intake. During generalization, the CS +, CS -, and generalization stimuli (GS; circles of intermediary sizes) were repeatedly presented. US expectancies, US desires, CS evaluations, and CS/GS-elicited ad libitum food intake functioned as outcome measures.

\subsection{Measures}

Ratings: computerized Visual Analogue Scales (VASs) were used to measure US expectancies ('To what extent do you expect to receive chocolate/crisps right now?'), US desires ('When looking at this picture, how strong is your desire for chocolate/crisps right now?'), and CS evaluations ('How pleasant do you find this picture?'). Anchors ranged from 0 (certainly not expect to receive chocolate/crisps/no desire at all/not pleasant at

\footnotetext{
${ }^{2}$ In this prior study, the post-acquisition CS + vs CS- differentiation in eating desires was $3.24( \pm 10.81)$ for the overweight group and 11.21 $( \pm 14.44)$ for the healthy weight group.
} 
Table 1

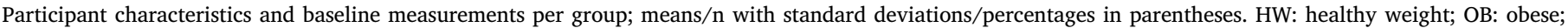
BMI: Body Mass Index; US: unconditioned stimulus; STAI: State and Trait Anxiety Inventory; EDE-Q: Eating Disorder Examination Questionnaire (global score).

\begin{tabular}{|c|c|c|c|c|}
\hline & HW & OB & t or $\chi^{2}(d f)^{*}$ & $\mathrm{p}$ \\
\hline$n$ & 40 & 45 & & \\
\hline BMI & $21.98(1.86)$ & $35.79(3.22)$ & $23.80(83)$ & $<.001$ \\
\hline Age & $43.38(12.17)$ & $44.02(10.25)$ & $0.27(83)$ & .79 \\
\hline Highest education [n(\%)] & & & $0.96(3)$ & .81 \\
\hline Lower & $5(12.50)$ & $5(11.11)$ & & \\
\hline Intermediate & $19(47.50)$ & $24(53.33)$ & & \\
\hline Higher & $11(27.50)$ & $13(28.89)$ & & \\
\hline University & $5(12.50)$ & $3(6.67)$ & & \\
\hline Non-psychotropic med use ${ }^{* *}[n(\%)]$ & $7(17.50)$ & $23(51.11)$ & & \\
\hline Baseline hunger & $36.78(25.15)$ & $41.04(27.73)$ & $0.74(83)$ & .46 \\
\hline Minutes since food intake & $145.75(50.78)$ & $140.30(50.35)$ & $0.49(82)$ & .62 \\
\hline US choice [n (\%)] & & & $1.47(1)$ & .23 \\
\hline Chocolate & $29(72.50)$ & $27(60.00)$ & & \\
\hline Crisps & $11(27.50)$ & $18(40.00)$ & & \\
\hline US liking & $71.38(24.57)$ & $67.31(22.71)$ & $0.79(83)$ & .43 \\
\hline STAI-S & $28.08(6.33)$ & $29.33(8.18)$ & $0.79(83)$ & .43 \\
\hline STAI-T & $31.48(6.50)$ & 35.33 (10.57) & $2.05(74.22)$ & .04 \\
\hline EDE-Q & $0.90(0.73)$ & $2.75(1.24)$ & $8.53(72.69)$ & $<.001$ \\
\hline
\end{tabular}

* Degrees of freedom vary due to missing data and violation of Levene's test for equality of variances.

** One obese participant unexpectedly reported using psychotropic medication (antidepressants) after participation. Excluding her data did not change the results and therefore, the reported analyses include this participant.

all) to 100 (certainly expect to receive chocolate/crisps/very strong desire/ very pleasant). Contingency awareness was assessed with an open question ("You sometimes received a piece of chocolate/a crisp during the computer task. When did you receive this?").

Food intake: ad libitum food intake was measured during a 10-min bogus taste test. Three white cubes (approximately $14 \mathrm{~cm}$ in height/ width/depth) were positioned next to each other on the table in front of the participant, with a generously filled bowl (containing the participant's US) placed on top of each of the cubes. The CS +, the CS - , and a GS were each depicted on one of the cubes on the side facing the participant. The circle sizes of the CS + and CS - precisely matched the circle sizes presented on the computer screen. The size of the GS was the average of the two most intermediate circles $(8.51 \mathrm{~cm})$. The position (left, right, or in the middle) of each cube (depicting the CS,$+ \mathrm{CS}-$, or GS) was counterbalanced across participants, so that each stimulus was placed left, in the middle, or right for an approximately equal number of participants in each group, to control for possible order effects on intake (participants may, for example, have a general tendency to consume most of a bowl placed in the middle). Participants were informed that the three types of chocolate/crisps presented on the cubes were from the same factory, but that there would be small differences in their taste. They were also told that they had to answer questions about these supposed differences and were allowed to taste as much or as little as they wanted from each food. The bowls were weighed before and after the session to calculate kcal consumption.

Hunger and US liking: VASs were used to measure hunger ('How hungry are you right now?') and US liking ('How much did you like the chocolate/crisps?'), with anchors ranging from 0 (not hungry at all/did not like it at all) to 100 (very hungry/liked it very much).

State-Trait Anxiety Questionnaire (STAI; Spielberger \& Gorsuch, 1983): the STAI is a 40-item self-report questionnaire with two subscales (trait and state anxiety, 20 items each). Items are scored on a four-point Likert scale ranging from 1 (not at all) to 4 (very much), higher total scores indicating higher levels of anxiety. Studies have demonstrated the reliability and (convergent) validity of both subscales of the STAI (Spielberger \& Gorsuch, 1983; Novy et al., 1993).

Eating desire frequency: frequency of eating desires was assessed by the question "How often during a day do you usually experience desires for food?". Response options were: 0 (never), 1 (rarely), 2 (sometimes), 3 (often), and 4 (almost all the time/all the time).

Eating Disorder Examination - Questionnaire (EDE-Q; Fairburn \&
Beglin, 1994): the EDE-Q is a 28-item questionnaire and is considered a valid and reliable self-report measure to assess eating psychopathology (Luce \& Crowther, 1999; Wilfley, Schwartz, Spurrell, \& Fairburn, 1997). Items are scored on a seven-point Likert scale ranging from 0 (never) to 6 (every day). The EDE-Q has four subscales (eating concerns, shape concerns, weight concerns, and eating restraint), and a global score can be calculated. Higher scores reflect greater levels of eating psychopathology. The EDE-Q is a considered a valid and reliable self-report measure for assessing eating psychopathology.

\subsection{Stimuli}

CSs: a small $(5.08 \mathrm{~cm})$ and a large (11.94) circle functioned as CSs (Lissek et al., 2008). Which circle functioned as the CS + or CS - was counterbalanced across participants.

GSs: eight intermediately sized circles functioned as the GSs, with the first GS having a 15\% larger diameter than the smallest circle, the second GS having a 30\% larger diameter than the smallest circle, etc (Lissek et al., 2008). This resulted in circle diameters of 5.84, 6.60, $7.38,8.13,8.89,9.65,10.41$, and $11.18 \mathrm{~cm}$.

USs: the US was either a small piece of milk chocolate (approximately $1 \mathrm{~g}$ ) or a small crisp (approximately $0.5 \mathrm{~g}$ ), depending on the preference of the participant. Participants could choose between two brands of chocolate (Tony Chocoloneley and Cote d'or) and two brands and three flavours of crisps (Lay's and Croky; salty, paprika, and bolognese).

\subsection{Acquisition and generalization task}

The acquisition and generalization paradigms were adapted from Lissek et al., 2008.

Acquisition consisted of twelve CS + and twelve CS - trials. Ten of the CS + trials were followed by a US. Trials were presented in a random order except that no more than two consecutive trials were of the same trial type. A trial proceeded as follows: the CS was presented for $10 \mathrm{~s}$, after which the expectancy VAS appeared under the CS. After completion, the desire VAS was presented. After this, if applicable, the US was provided, which was placed in front of the participant by an experimenter sitting behind a screen. The inter-trial interval was $15 \mathrm{~s}$. After acquisition, CS liking was assessed by presenting each CS once with a CS evaluation VAS. 
Generalization comprised three blocks that each included two $\mathrm{CS}+$ trials (one followed by a US), two CS - trials, and one trial for each GS (never reinforced by a US). Within each block, trials were presented in a random order, and a trial proceeded the same way as in acquisition. After the three blocks, all CSs and GSs were presented once (in a random order) accompanied by a CS evaluation VAS.

\subsection{Procedure}

Participants were individually seen between 12 p.m. and 7 p.m. After arrival, the participant gave written consent and completed a hunger VAS. She was then structed that she would see pictures, answer questions, and sometimes receive something to eat. She was not told about the CS - US contingency but instructed that she might learn to predict when she could taste something if she attends to the figures. Next, the acquisition and then the generalization task was completed. After this, the participant completed the US liking VAS, the bogus taste test, the contingency awareness question, the desire frequency question, a question about her idea of study's hypothesis, the STAI, the EDE$\mathrm{Q}$, demographic questions, and the time of pre-experimental food intake. Finally, the participants' height and weight were measured, she was thanked and compensated for participation.

\subsection{Data reduction and statistical analyses}

The twelve acquisition trials per CS - type were averaged into six blocks. The eight generalization stimuli were averaged into four classes (with class 1 resembling the CS - more and class 4 resembling the $\mathrm{CS}+$ more) with responses being averaged over generalization blocks, when applicable. Acquisition of US expectancies and eating desires was analyzed using 2 (CS - type: CS + vs. CS - ) $\times 6$ (Block) $\times 2$ (Group: $\mathrm{HW}$ vs. $\mathrm{OB}$ ) repeated-measures ANOVAs, with $\mathrm{CS}-$ type and Block as within-subjects factors and Group as between-subjects factors. Acquisition of conditioned evaluations was also examined using a repeated-measures ANOVA, with CS - type as within-subjects and Group as between-subjects factors. Group differences in contingency awareness (defined as having correctly indicated the CS-US contingency in the open question) were analyzed using a Pearson's chi-square test. Generalization of US expectancies, eating desires, and CS evaluations was examined using 6 (Stimulus-type: CS - , class 1, class 2, class 3, class $4, \mathrm{CS}+$ ) $\times 2$ (Group: HW vs. OB) repeated-measures ANOVAs, with Stimulus-type and Group as between-subjects factors. Food intake was also analyzed using a repeated-measures ANOVA, with stimulustype (CS +, GS, CS -) as within-subject factor and Group as between subjects factor. Desire frequency was coded as either low (never, rarely, or sometimes, $n=44$ ) or high (often or all the time, $n=41$ ), ${ }^{3}$ and included as between-subjects factor in the main analyses (instead of Group). Greenhouse-Geisser epsilon corrections are reported for repeated measures ANOVAs when sphericity was violated.

Finally, to examine whether trait and state anxiety scores were related to individual differences in responding, easy-to-interpret acquisition and generalization indexes were calculated for US expectancies, US desires and CS evaluations. Acquisition indexes were calculated by subtracting mean $\mathrm{CS}$ - responding from mean CS + responding during acquisition (US expectancies and US desires) or post acquisition (CS evaluations) (Winkelmann et al., 2016). As generalization indexes, a linear deviation score was calculated for each dependent variable by subtracting averaged $\mathrm{CS}+$ and $\mathrm{CS}$ - responding from (averaged) GS responding (Kaczkurkin et al., 2017); this score thus reflects the deviation of the generalization gradient from the linear midpoint, with more positive scores indicating more generalization. ${ }^{4}$ Correlations were

\footnotetext{
${ }^{3}$ Almost all participants either answered "sometimes" ( $\left.=41\right)$ or "often" $(n=40)$.

${ }^{4}$ One may argue that individuals prone to overgeneralization would exhibit
}

computed between the acquisition and generalization indexes and anxiety scores.

\section{Results}

\subsection{Acquisition}

US expectancies and contingency learning: participants successfully acquired differential US expectancies, as indicated by a significant CStype $\times$ Block interaction, $F(3.47,288.20)=83.17, \quad p<.001$, $\eta_{\mathrm{p}}{ }^{2}=0.50$ (see Fig. 1, upper panel). This resulted in a significant CS + vs. CS - differentiation on the last acquisition block, $F$ (1, $83)=286.19, p<.001, \eta_{p}{ }^{2}=0.78$. However, no significant group differences were found in the course of acquisition nor in the last block, CS-type $\times$ Trial $\times$ Group: $F(3.47,288.20)=1.21, p=.31, \eta_{\mathrm{p}}{ }^{2}=0.01$, main effect of Group: $F(1,83)=3.52, p=.06, \eta_{\mathrm{p}}{ }^{2}=0.04$; last block: CS-type $\times$ Group and main effect of Group: $F s<1$. In line with this, groups did not differ in contingency awareness as assessed in the open question (HW: $n=32$ or $80 \%$ contingency aware; OB: $n=35$ or $78 \%$ ), $\chi^{2}(1, N=85)=0.06, p=.80$, Cramer's phi $=.03$.

US desires: differential US desires were successfully acquired (CStype $\times$ Block $), F(2.77,229.78)=9.07, p<.001, \eta_{\mathrm{p}}{ }^{2}=0.10$, resulting in significantly heightened desires to the CS + vs. CS - on the last block, $F(1,83)=24.43, p<.001, \eta_{\mathrm{p}}{ }^{2}=0.23$ (see Fig. 1 , lower panel). No significant differences across groups were found, CStype $\times$ Trial $\times$ Group: $F(2.77,229.78)=1.60, p=.19, \eta_{\mathrm{p}}{ }^{2}=0.02$, main effect of Group: $F<1$; CS-type $\times$ Group and main effect of Group on the last block: $F$ s $<1$.

CS evaluations: after acquisition, participants evaluated the CS + more positively than the CS $-, F(1,83)=8.63, p=.004$, $\eta_{\mathrm{p}}{ }^{2}=0.09$, again with no differences across the groups, CStype $\times$ Group and main effect of Group: $F$ s $<1$ (HW CS + : $\mathrm{M}=57.10$, $\mathrm{SD}=25.16 ; \mathrm{HW} \mathrm{CS}-:$ 45.55, $\mathrm{SD}=26.12 ; \mathrm{OB} \mathrm{CS}+:$ 58.16, $\mathrm{SD}=31.09$; $\mathrm{OB} \mathrm{CS}-: \mathrm{M}=40.22, \mathrm{SD}=31.17$ ).

\subsection{Generalization}

Because acquisition is a prerequisite for generalization (Ahmed \& Lovibond, 2015; Lenaert, van de Ven, Kaas, \& Vlaeyen, 2016), participants who did not acquire differential US expectancies (differentiation last block < 20), US desires (differentiation last block $<5$ ) and CS evaluations (post-acquisition differentiation $<5$ ) were excluded from the respective analyses. For the US expectancies and CS evaluations analyses, one vs. two additional participants were excluded who suddenly shifted their responses to the CS + and CS - during generalization. The analyses are based on the remaining sample (US expectancies: $\mathrm{OB} \mathrm{n}=35$, $\mathrm{HW} \mathrm{n}=35$; US desires: $\mathrm{OB} \mathrm{n}=18$, $\mathrm{HW}$ $\mathrm{n}=16$; CS evaluations: $\mathrm{OB} \mathrm{n}=22$, $\mathrm{HW} \mathrm{n}=16$ ). However, when including the entire sample, the outcomes of the analyses were largely similar; when this was not the case this is indicated below. Finally, because individual differences might be especially pronounced when GSs are first presented (i.e., in the first block) due to extinction of generalized responding, analyses were repeated for the first block only, when applicable. Outcomes of these analyses were similar to those including averaged scores; therefore, only the latter are reported.

US expectancies: a main effect of Stimulus-type was found, $F(2.73$, 185.85) $=236.89, p<.001, \eta_{\mathrm{p}}{ }^{2}=0.78$. Within-subjects contrasts

\section{(footnote continued)}

(more) generalization to the CS-, which would result, ceteris paribus, in a lower generalization score. However, theory predicts that responding (over)generalizes as a function of stimulus similarity, and this is also reflected in GS responding; therefore, a tendency to overgeneralize should have considerably more impact on more similar GSs than on the dissimilar CS-, hence resulting in a positive score. 


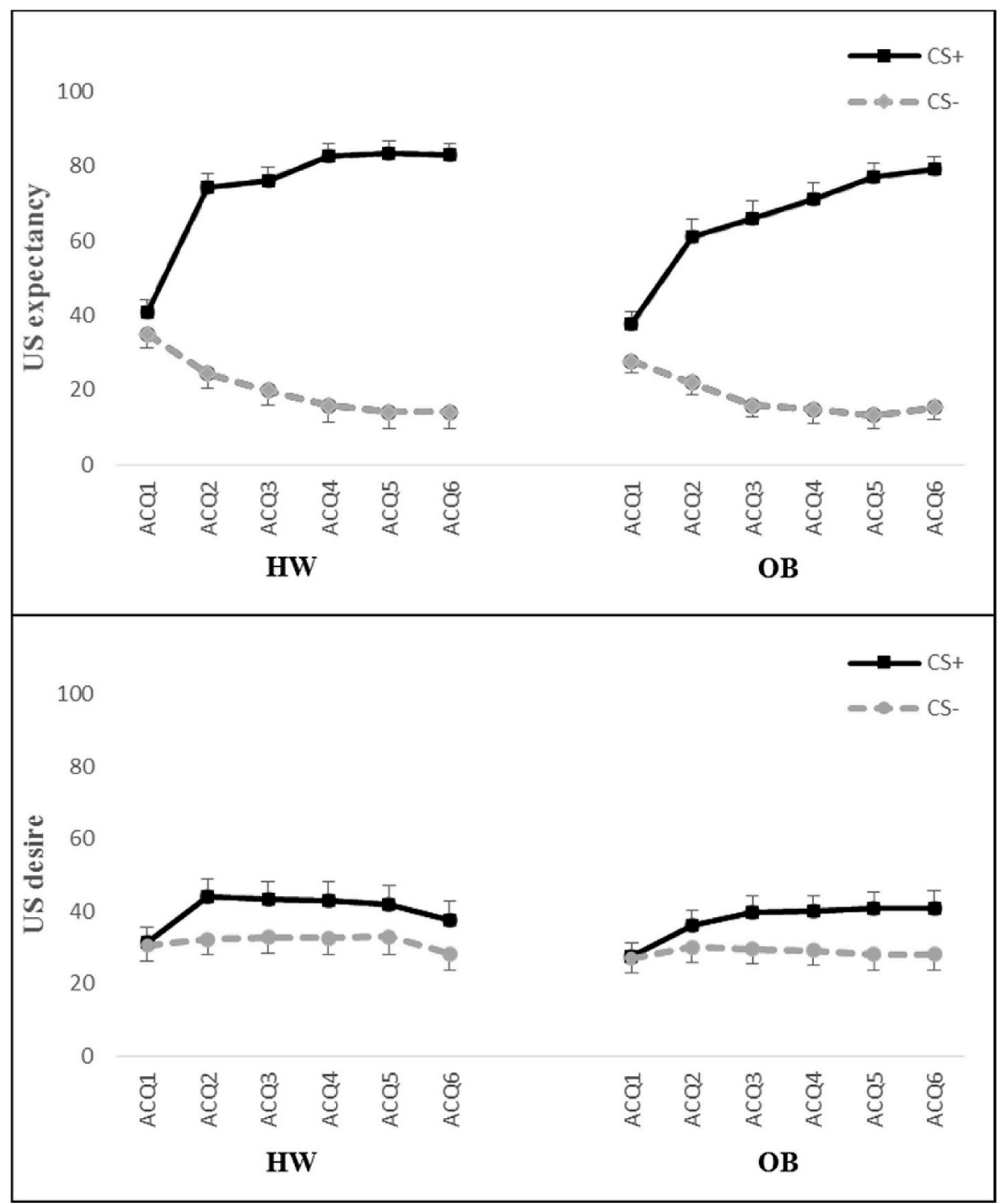

Fig. 1. Acquisition of US expectancies and US desires across groups, CS - type, and acquisition block (+SEM). HW: healthy weight; OB: obese; US: unconditioned stimulus; CS +: stimulus paired with the US; CS -: stimulus not paired with the US.

showed linear and quadratic trends of this effect, $F(1,68)=650.95$, $p<.001, \eta_{\mathrm{p}}{ }^{2}=0.91 ; F(1,68)=56.42, p<.001, \eta_{\mathrm{p}}{ }^{2}=0.45$, indicating linear and quadratic increases in US expectancies to stimuli with greater similarity to the CS + (see Fig. 2, upper panel). However, the Group $\times$ Stimulus-type interaction was not significant, $F<1$ (main effect of Group: $F<1$ ). Thus, these findings suggest that US expectancies generalize as a function of stimulus similarity, but that healthy weight vs. obese individuals do not differ in generalization.

US desires: a main effect of stimulus-type was found, $F(1.70$, $54.50)=33.88, p<.001, \eta_{\mathrm{p}}{ }^{2}=0.51$, with linear and quadratic increases in desires to stimuli with increasing CS + similarity, $F(1$, $32)=45.87, p<.001, \eta_{\mathrm{p}}^{2}=0.58 ; \quad F(1,32)=15.08, p<.001$, $\eta_{\mathrm{p}}{ }^{2}=0.32$ (see Fig. 2, middle panel). The Group $\times$ Stimulus-type interaction and the main effect of Group were not significant, $F \mathrm{~s}<1$.

CS evaluations: again, analyses revealed a main effect of Stimulustype, $F(2.40,86.52)=81.35, p<.001, \eta_{\mathrm{p}}{ }^{2}=0.69$, and significant linear and quadratic trends of this effect, $F(1,36)=138.58, p<.001$, $\eta_{\mathrm{p}}{ }^{2}=0.79, F(1,36)=16.02, p<.001, \eta_{\mathrm{p}}{ }^{2}=0.31$ (quadratic trend entire sample: $F(1,83)=3.62, p=.06, \eta_{\mathrm{p}}{ }^{2}=0.04$ ) (see Fig. 2 , lower panel). The Group $\times$ Stimulus-type interaction and the main effect of Group were not significant, Fs $<1$.

\subsection{Ad libitum food intake}

As expected, a main effect of stimulus-type was found, $F(1.72$, 142.39 ) $=8.30, p=.001, \eta_{\mathrm{p}}{ }^{2}=0.09$ (entire sample), with follow-up analyses indicating that both $\mathrm{CS}+, F(1,83)=12.38, p=.001$, $\eta_{\mathrm{p}}{ }^{2}=0.13$, and GS intake, $F(1,83)=8.03, p=.006, \eta_{\mathrm{p}}{ }^{2}=0.09$, was significantly higher than CS - intake (CS + vs. GS: $F(1,83)=3.19$, $p=.08, \eta_{\mathrm{p}}{ }^{2}=0.04$ ) (see Fig. 3). The main effect of Group and its interaction with Stimulus-type were not significant, $F(1,83)=2.88$, $p=.09, \eta_{\mathrm{p}}{ }^{2}=0.03, F(1.72,142.39)=1.70, p=.19, \eta_{\mathrm{p}}{ }^{2}=0.02$, respectively. Thus, these data demonstrate that 1) the food-associated stimulus (CS + ) stimulated food intake compared with the CS - , and 2) this potentiation was (at least partly) transferred to a stimulus that resembled the CS+ (i.e., the GS).

\subsection{Moderators}

Desire frequency: obese vs. healthy weight individuals were about twice as likely to report a high frequency of eating desires in their daily life (HW: $n=13$ or $32.50 \%$; OB: $n=28$ or $62.22 \%$ ), $\chi^{2}$ (1, $N=85)=7.49, p=.006$, Cramer's Phi $=.30$. However, including desire frequency as a between-subjects factor in the repeated-measures 


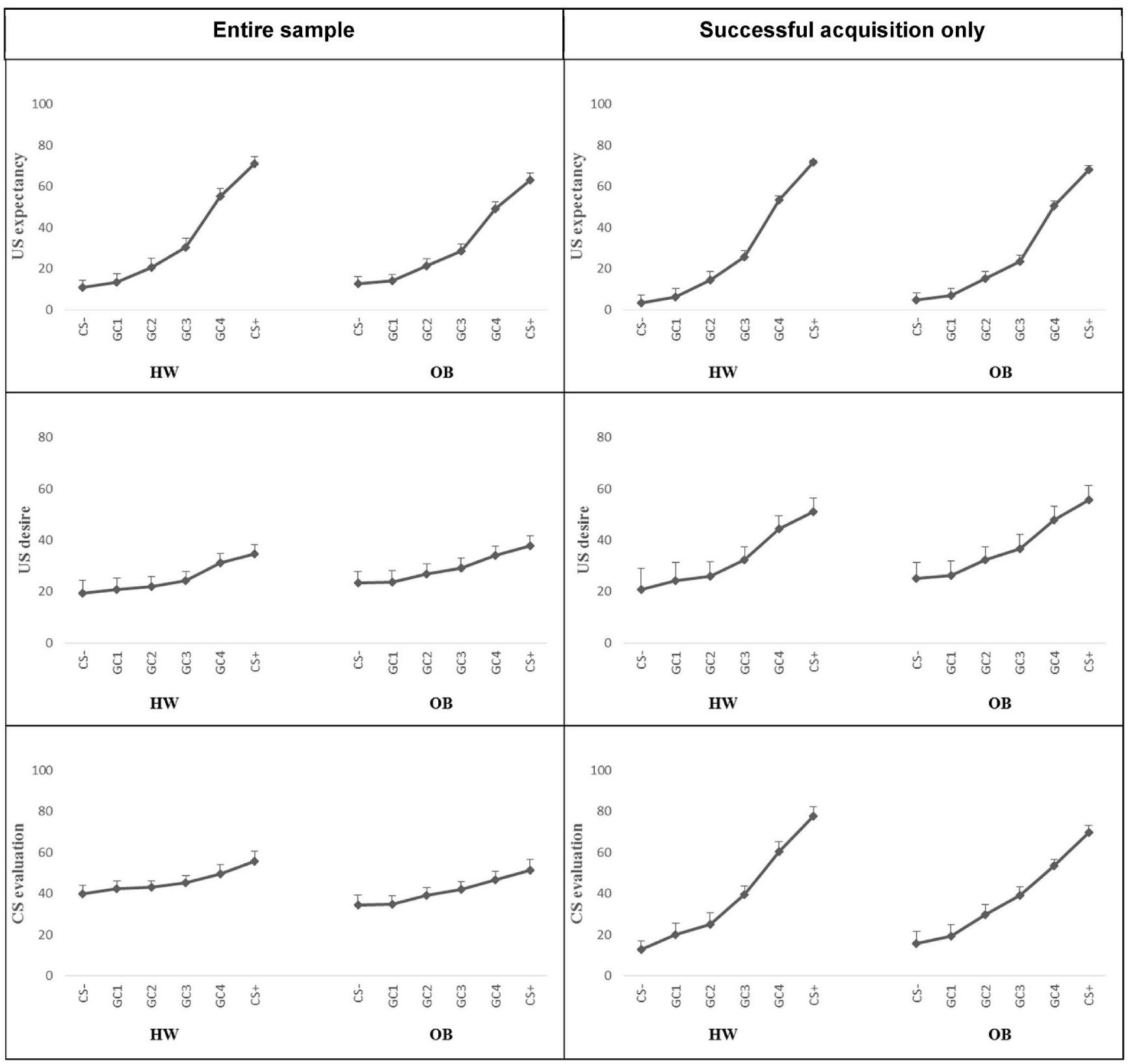

Fig. 2. Generalization gradients of US expectancies, US desires, and CS evaluations across groups, and stimulus-type (+SEM). Left panels: entire sample $(N=85)$. Right panels: subsample of participants who showed successful acquisition of responding (see section 'Generalization' for details). HW: healthy weight; OB: obese; US: unconditioned stimulus; CS +: stimulus paired with the US; GC: generalization stimulus (class); CS - : stimulus not paired with the US.

ANOVAs showed that reporting a low vs. high desire frequency was not related to differences in acquisition nor generalization of US expectancies [differentiation last acquisition block: $F(1,83)=1.18$, $p=.28, \eta_{\mathrm{p}}{ }^{2}=0.01$, all other $F \mathrm{~s}<1$ ], US desires [all $F \mathrm{~s}<1$ ], CS evaluations [acquisition: $F(1,83)=1.45, p=.23, \eta_{\mathrm{p}}{ }^{2}=0.02$, generalization: $F<1]$, or cued food intake $[F<1]$.

State and trait anxiety: in line with the hypotheses, the correlation between trait anxiety scores and generalization of CS evaluations was marginally significant, $r=0.32, p=.054$. Exploratory analyses suggested that this correlation was specific for the obese group, $r=.43$, $p=.046$ (HW: $r=0.07, p=.79$ ). No other correlations were found between state or trait anxiety scores and the acquisition (largest $r=0.18$, smallest $p=.09$ ) and generalization indexes (largest $r=0.30$, smallest $p=.09$ ). Including the entire sample in the analyses revealed no significant correlations. See Table 1 for mean trait and state anxiety scores per group.

\section{Discussion}

The main aim of this study was to examine whether obese vs. healthy weight females show 1) worse discrimination learning and 2) greater generalization of appetitive responding. In addition, it was investigated whether increased self-reported daily desire frequency and trait and state anxiety are associated with a worse acquisition and greater generalization. Results showed successful acquisition across all outcome measures, as reflected by heightened US expectancies, desires to eat, evaluations, and ad libitum food intake to the CS + vs. CS - . The acquired appetitive responses also generalized: participants showed stronger responding to stimuli (GSs) that were more similar to the CS +. However, no evidence was found for differences in responding as a function of weight status or desire frequency. Trait anxiety was associated with more generalization of acquired CS evaluations.

The finding that human appetitive responding can generalize is 


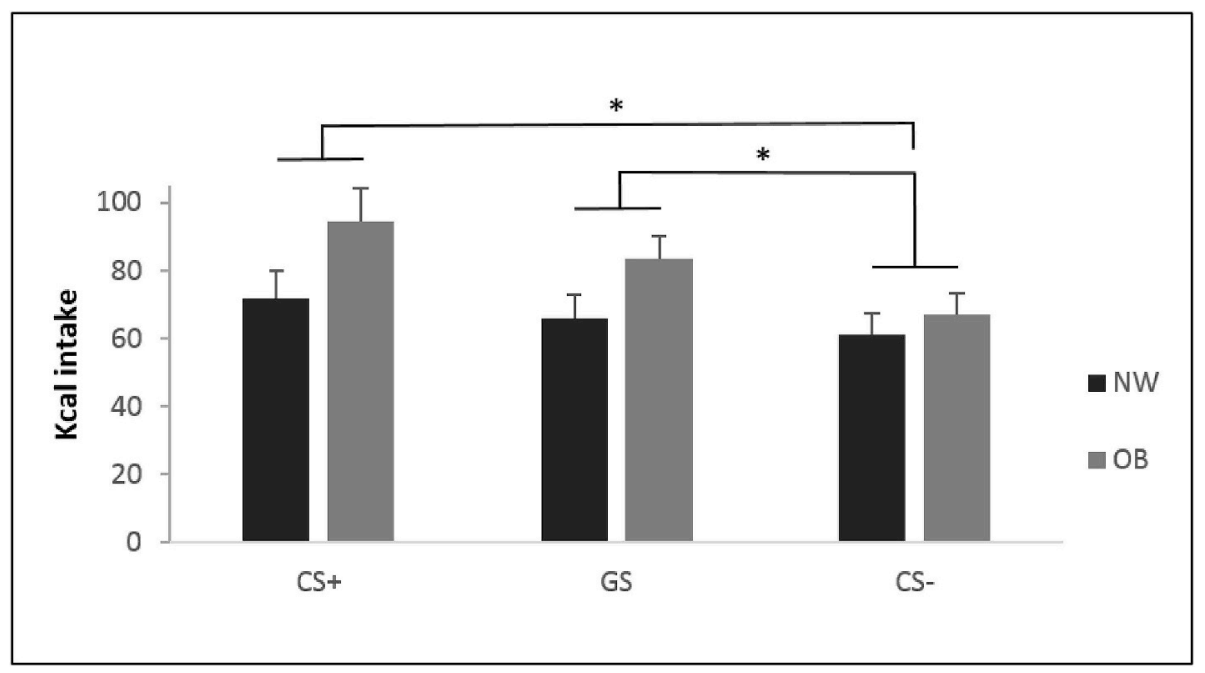

Fig. 3. Total kcal intake across groups and stimulus type (+SEM). HW: healthy weight; OB: obese; US: unconditioned stimulus; CS + : stimulus paired with the US; GS: generalization stimulus; $\mathrm{CS}-$ : stimulus not paired with the US.

interesting in its own right: it shows that stimuli that resemble original $\mathrm{CS}+\mathrm{s}$ but that were never actually paired with eating are able to stimulate appetitive responding including actual food consumption in humans. ${ }^{5}$ This provides an additional mechanism by which learned cues can promote appetitive responding and (over)eating in real-life, i.e., by increasing the number of cues that elicit appetitive reactivity. For example, generalization may cause a person who learned to eat when feeling sad $(\mathrm{CS}+)$ to also exhibit appetitive responding to other negative emotions (e.g., feeling stressed or bored), a person who always eats crisps when watching a movie at home $(\mathrm{CS}+)$ to experience appetitive reactivity when watching a movie at the cinema, and a person who learns to eat a cookie with their afternoon tea $(\mathrm{CS}+)$ to show reactivity when consuming any hot beverage. Weight loss interventions may ultimately benefit from insights into the role of generalization processes in (over)eating. For example, interventions aimed at the extinction of appetitive responding (cue exposure therapy, e.g., Boutelle et al., 2014; Jansen, Van Den Hout, De Loof, Zandbergen, \& Griez, 1989; Jansen, 1998; Schyns, van den Akker, Roefs, Hilberath, \& Jansen, 2018; Schyns, Roefs, Smulders, \& Jansen, 2018; Schyns, Roefs, Mulkens, \& Jansen, 2016) can, theoretically, be optimized by carefully identifying the $\mathrm{CS}+\mathrm{s}$ originally associated with food intake and including these during therapy: extinction of the original $\mathrm{CS}+\mathrm{s}$ can be expected to effectively diminish GS-elicited responding as well (Vervoort, Vervliet, Bennett, \& Baeyens, 2014).

We hypothesized that obese individuals, and individuals who experience frequent eating desires, would exhibit a greater generalization of appetitive responding. No evidence was found for this, which suggests that inter-individual differences in the generalization process do not strongly account for individual differences in desire frequency, overeating and weight. At the same time, the present study provided initial evidence that overgeneralization might be a characteristic only of a certain subgroup of obese individuals, i.e., those high in trait anxiety. This could be in line with findings of a recent study showing that anxiety patients (vs. healthy controls) overgeneralized after appetitive conditioning with monetary rewards (Laufer et al., 2016). ${ }^{6}$ Together, these interesting findings could suggest that (vulnerability to) anxiety is not a specific risk factor for overgeneralization of fear, but may instead

\footnotetext{
${ }^{5}$ A recent appetitive conditioning study provided evidence for generalization in a healthy student sample with regards to US expectancies and valence, and to some extent, startle responses (Andreatta \& Pauli, 2019).

${ }^{6}$ Perhaps relatedly, a prior study suggested that acute stress promotes overgeneralization of appetitive responding (Kruse, León, Stalder, Stark, \& Klucken, 2018).
}

reflect a more general predisposition towards overgeneralization across aversive and appetitive domains. Given the sparse amount of research on this topic however, and that the anxiety-generalization relationship was restricted to a single outcome measure in the current study (and to individuals who showed successful acquisition), additional research is necessary to determine if and how obesity, anxiety, and generalization are related.

As outlined in the Introduction, prior findings have suggested that overweight and obesity are characterized by appetitive learning deficits (van den Akker et al., 2017; Coppin et al., 2014; Zhang et al., 2014), whereas other findings suggested better learning in overweight/obesity (Meemken et al., 2018; Meyer et al., 2015). The current study adds a third possibility by suggesting that obese and healthy-weight individuals do not differ in appetitive learning. This mixed pattern of findings across studies could indicate that whether, and in which direction, overweight/obese individuals show altered appetitive learning depends on certain (to date unidentified) factors. ${ }^{7}$ Unfortunately, any comparisons between the current and prior studies that might shed light on these factors are complicated by their large diversity in the paradigm that was used (e.g., how the US was provided, how many trials were given, the rate of reinforcement, what was measured, and which instructions the participants received) as well as sample selection (e.g., how the sample was recruited and if and how groups were matched). However, more generally, mixed outcomes of studies examining reactivity to the sight and/or smell of food (i.e., food cues) in overweight/obese vs. healthy weight individuals are actually quite common (Boswell \& Kober, 2016; Ziauddeen, Farooqi, \& Fletcher, 2012). It has recently been argued that these inconsistencies may be explained by food cue processing not being a static process, but being heavily influenced by cognitive factors such as one's current focus of attention (e.g., health vs. pleasure) or cognitive regulation strategies (e.g., suppression) (Roefs, Franssen, \& Jansen, 2018). For example, in one study, neural food cue reactivity was increased in overweight (vs. healthy weight) individuals when participants were instructed to focus on taste aspects of food; in contrast, when no additional instructions were given overweight individuals showed reduced food cue reactivity (Frankort et al., 2012). Presumably, due to their strong ambivalence towards food cues, overweight individuals focused predominantly on health aspects in the latter case, resulting in reduced reward processing (Frankort et al., 2012). Perhaps the inconsistent findings across appetitive

\footnotetext{
${ }^{7}$ Importantly, this rests on the assumption that all studies contain replicable findings, and are not due to, for example, limited sample size.
} 
conditioning studies examining weight status can be similarly accounted for by such cognitive factors, which were not manipulated nor held constant in any of the studies. This remains an interesting open question for future research.

Finally, individuals consumed significantly more food (crisps or chocolate) from bowls that depicted the food-associated stimulus (CS + ) vs. control stimulus ( $\mathrm{CS}-$ ). Given that human conditioning studies rarely examine actual food intake, this finding is important: it provides among the first evidence that conditioned cues not only elicit psychological and physiological reactivity in humans but can, crucially, also alter actual food intake (Birch, McPhee, Sullivan, \& Johnson, 1989; Ridley-Siegert, Crombag, \& Yeomans, 2015; van den Akker et al., 2013). ${ }^{8}$ This is in line with predictions of learning models of eating behaviour, and underlines the importance of associative learning mechanisms in human eating behaviour (Bouton, 2011; Jansen, 1998; van den Akker et al., 2018).

In sum, the current findings indicate that conditioned cues elicit heightened appetitive responding including food intake, and that appetitive responding generalizes to stimuli that resemble the conditioned food cue. The findings also show no differences in acquisition and generalization as a function of weight status (healthy weight vs obese) or self-reported desire frequency, but provide initial evidence for overgeneralization to be a characteristic only of a subgroup of obese individuals that scores high on trait anxiety. Future research should focus on identifying factors that underlie the inconsistent findings with regard to differences between healthy weight and obese individuals in appetitive conditioning.

\section{Availability of data and materials}

The data and study materials have been publicly archived. The data are not publicly available as participants did not provide specific consent for this, and due to concerns that de-anonymisation might be (come) possible when coupling datasets. However, access can be requested at https://hdl.handle.net/10411/JBC6EA.

\section{Acknowledgements}

The authors would like to thank Ann Meulders for her helpful comments on the design of this study. The authors received no funding from an external source.

\section{References}

Ahmed, O., \& Lovibond, P. F. (2015). The impact of instructions on generalization of conditioned fear in humans. Behavior Therapy, 46(5), 597-603. https://doi.org/10. 1016/j.beth.2014.12.007.

van den Akker, K., Jansen, A., Frentz, F., \& Havermans, R. C. (2013). Impulsivity makes more susceptible to overeating after contextual appetitive conditioning. Appetite, 70, 73-80. https://doi.org/10.1016/j.appet.2013.06.092.

van den Akker, K., Schyns, G., \& Jansen, A. (2017). Altered appetitive conditioning in overweight and obese women. Behaviour research and therapyhttps://doi.org/10.1016/j. brat.2017.09.006.

van den Akker, K., Schyns, G., \& Jansen, A. (2018). Learned overeating: Applying prin ciples of pavlovian conditioning to explain and treat overeating. Current Addiction Reports, 1-9. https://doi.org/10.1007/s40429-018-0207-x.

Andreatta, M., \& Pauli, P. (2019). Generalization of appetitive conditioned responses. Psychophysiologye13397.

Birch, L. L., McPhee, L., Sullivan, S., \& Johnson, S. (1989). Conditioned meal initiation in young children. Appetite, 13(2), 105-113. https://doi.org/10.1016/0195-6663(89) 90108-6.

Blechert, J., Testa, G., Georgii, C., Klimesch, W., \& Wilhelm, F. H. (2016). The Pavlovian craver: Neural and experiential correlates of single trial naturalistic food conditioning in humans. Physiology \& Behavior, 158, 18-25. https://doi.org/10.1016/j.physbeh. 2016.02.028.

Boswell, R. G., \& Kober, H. (2016). Food cue reactivity and craving predict eating and

\footnotetext{
${ }^{8}$ For well-established effects of Pavlovian stimuli on human instrumental responding for more abstract food points, see e.g. Cartoni, Balleine, \& Baldassarre, 2016; Watson, Wiers, Hommel, Gerdes, \& de Wit, 2017.
}

weight gain: A meta-analytic review. Obesity Reviews, 17(2), 159-177. https://doi. org/10.1111/obr.12354.

Boutelle, K. N., Zucker, N., Peterson, C. B., Rydell, S., Carlson, J., \& Harnack, L. J. (2014). An intervention based on Schachter's externality theory for overweight children: The regulation of cues pilot. Journal of Pediatric Psychology, jst142.

Bouton, M. E. (2011). Learning and the persistence of appetite: Extinction and the motivation to eat and overeat. Physiology \& Behavior, 103(1), 51-58. https://doi.org/10. 1016/j.physbeh.2010.11.025.

Cartoni, E., Balleine, B., \& Baldassarre, G. (2016). Appetitive Pavlovian-instrumental transfer: a review. Neuroscience \& Biobehavioral Reviews, 71, 829-848.

Chao, A., Grilo, C. M., White, M. A., \& Sinha, R. (2014). Food cravings, food intake, and weight status in a community-based sample. Eating Behaviors, 15(3), 478-482. https://doi.org/10.1016/j.eatbeh.2014.06.003.

Coppin, G., Nolan-Poupart, S., Jones-Gotman, M., \& Small, D. M. (2014). Working memory and reward association learning impairments in obesity. Neuropsychologia, 65, 146-155. https://doi.org/10.1016/j.neuropsychologia.2014.10.004.

Eaton, N. R., Rodriguez-Seijas, C., Carragher, N., \& Krueger, R. F. (2015). Transdiagnostic factors of psychopathology and substance use disorders: A review. Social Psychiatry and Psychiatric Epidemiology, 50(2), 171-182. https://doi.org/10.1007/s00127-0141001-2.

Fairburn, C. G., \& Beglin, S. J. (1994). Assessment of eating disorders: Interview or self-report questionnaire? International Journal of Eating Disorders, 16, 363-370.

Frankort, A., Roefs, A., Siep, N., Roebroeck, A., Havermans, R., \& Jansen, A. (2012). Reward activity in satiated overweight women is decreased during unbiased viewing but increased when imagining taste: An event-related fMRI study. International Journal of Obesity, 36(5), 627-637. https://doi.org/10.1038/ijo.2011.213.

Gariepy, G., Nitka, D., \& Schmitz, N. (2010). The association between obesity and anxiety disorders in the population: A systematic review and meta-analysis. International Journal of Obesity, 34(3), 407-419. https://doi.org/10.1038/ijo.2009.252 Retrieved from.

Gazendam, F. J., Kamphuis, J. H., \& Kindt, M. (2013). Deficient safety learning characterizes high trait anxious individuals. Biological Psychology, 92(2), 342-352. https://doi.org/10.1016/J.BIOPSYCHO.2012.11.006.

Haddad, A. D. M., Pritchett, D., Lissek, S., \& Lau, J. Y. F. (2012). Trait anxiety and fear responses to safety cues: Stimulus generalization or sensitization? Journal of Psychopathology and Behavioral Assessment, 34(3), 323-331. https://doi.org/10.1007/ s10862-012-9284-7.

Hermans, D., Baeyens, F., \& Vervliet, B. (2013). Generalization of acquired emotional responses. Handbook of Cognition and Emotion, 117-134.

Jansen, A. (1998). A learning model of binge eating: Cue reactivity and cue exposure. Behaviour Research and Therapy, 36(3), 257-272. https://doi.org/10.1016/S00057967(98)00055-2.

Jansen, A., Schyns, G., Bongers, P., \& Akker, K. van den (2016). From lab to clinic: Extinction of cued cravings to reduce overeating. Physiology \& Behavior. https://doi. org/10.1016/j.physbeh.2016.03.018.

Jansen, A., Van Den Hout, M. A., De Loof, C., Zandbergen, J., \& Griez, E. (1989). A case of bulimia successfully treated by cue exposure. Journal of Behavior Therapy and Experimental Psychiatry, 20(4), 327-332. https://doi.org/10.1016/0005-7916(89) 90064-5.

Kaczkurkin, A. N., Burton, P. C., Chazin, S. M., Manbeck, A. B., Espensen-Sturges, T., Cooper, S. E., et al. (2017). Neural substrates of overgeneralized conditioned fear in PTSD. American Journal of Psychiatry, 174(2), 125-134. https://doi.org/10.1176/ appi.ajp.2016.15121549.

Kruse, O., León, I. T., Stalder, T., Stark, R., \& Klucken, T. (2018). Altered reward learning and hippocampal connectivity following psychosocial stress. Neurolmage, 171, 15-25.

Kube, J., Mathar, D., Horstmann, A., Kotz, S. A., Villringer, A., \& Neumann, J. (2017) Altered monetary loss processing and reinforcement-based learning in individuals with obesity. Brain imaging and behavior, 1-19.

Kuhn, M., Mertens, G., \& Lonsdorf, T. B. (2016). State anxiety modulates the return of fear. International Journal of Psychophysiology, 110, 194-199. https://doi.org/10. 1016/J.IJPSYCHO.2016.08.001.

Laufer, O., Israeli, D., \& Paz, R. (2016). Behavioral and neural mechanisms of overgeneralization in anxiety. Current Biology, 26(6), 713-722. https://doi.org/10.1016/ j.cub.2016.01.023.

Lenaert, B., van de Ven, V., Kaas, A. L., \& Vlaeyen, J. W. S. (2016). Generalization on the basis of prior experience is predicted by individual differences in working memory. Behavior Therapy, 47(1), 130-140. https://doi.org/10.1016/j.beth.2015.10.001.

Lissek, S., Biggs, A. L., Rabin, S. J., Cornwell, B. R., Alvarez, R. P., Pine, D. S., et al. (2008). Generalization of conditioned fear-potentiated startle in humans: Experimental validation and clinical relevance. Behaviour Research and Therapy, 46(5), 678-687.

Lissek, S., \& van Meurs, B. (2015). Learning models of PTSD: Theoretical accounts and psychobiological evidence. International Journal of Psychophysiology, 98(3), 594-605.

Lonsdorf, T. B., \& Merz, C. J. (2017). More than just noise: Inter-individual differences in fear acquisition, extinction and return of fear in humans - biological, experiential, temperamental factors, and methodological pitfalls. Neuroscience \& Biobehavioral Reviews, 80, 703-728. https://doi.org/10.1016/J.NEUBIOREV.2017.07.007.

Luce, K. H., \& Crowther, J. H. (1999). The reliability of the eating disorder examination—self-report questionnaire version (EDE-Q). International Journal of Eating Disorders, 25(3), 349-351.

Meemken, M. T., Kube, J., Wickner, C., \& Horstmann, A. (2018). Keeping track of promised rewards: Obesity predicts enhanced flexibility when learning from observation. Appetite, 131, 117-124. https://doi.org/10.1016/J.APPET.2018.08.029.

Meyer, M. D., Risbrough, V. B., Liang, J., \& Boutelle, K. N. (2015). Pavlovian conditioning to hedonic food cues in overweight and lean individuals. Appetite, 87, 56-61. https:// doi.org/10.1016/j.appet.2014.12.002. 
Nederkoorn, C., Smulders, F. T. Y., \& Jansen, A. (2000). Cephalic phase responses, craving and food intake in normal subjects. Appetite, 35(1), 45-55. https://doi.org/10.1006/ appe.2000.0328.

Novy, D. M., Nelson, D. V., Goodwin, J., \& Rowzee, R. D. (1993). Psychometric comparability of the State-Trait Anxiety Inventory for different ethnic subpopulations. Psychological Assessment, 5, 343-349. https://doi.org/10.1037/1040-3590.5.3.343.

Ogden, C. L., Carroll, M. D., Lawman, H. G., Fryar, C. D., Kruszon-Moran, D., Kit, B. K., \& Flegal, K. M. (2016). Trends in obesity prevalence among children and adolescents in the United States, 1988-1994 through 2013-2014. Jama, 315(21), 2292-2299.

Ridley-Siegert, T. L., Crombag, H. S., \& Yeomans, M. R. (2015). Whether or not to eat: A controlled laboratory study of discriminative cueing effects on food intake in humans. Physiology \& Behavior, 152, 347-353. https://doi.org/10.1016/j.physbeh.2015.06. 039 Part.

Roefs, A., Franssen, S., \& Jansen, A. (2018). The dynamic nature of food reward processing in the brain. Current Opinion in Clinical Nutrition and Metabolic Care, 21(6), 444-448. https://doi.org/10.1097/MCO.0000000000000504.

Schyns, G., Roefs, A., Mulkens, S., \& Jansen, A. (2016). Expectancy violation, reduction of food cue reactivity and less eating in the absence of hunger after one food cue exposure session for overweight and obese women. Behaviour Research and Therapy, 76, 57-64.

Schyns, G., Roefs, A., Smulders, F. T., \& Jansen, A. (2018). Cue exposure therapy reduces overeating of exposed and non-exposed foods in obese adolescents. Journal of Behavior Therapy and Experimental Psychiatry, 58, 68-77.

Schyns, G., van den Akker, K., Roefs, A., Hilberath, R., \& Jansen, A. (2018). What works better? Food cue exposure aiming at the habituation of eating desires or food cue exposure aiming at the violation of overeating expectancies? Behaviour Research and Therapy, 102, 1-7. https://doi.org/10.1016/j.brat.2017.12.001.

Spielberger, C. D., \& Gorsuch, R. L. (1983). Manual for the state-trait anxiety inventory. Palo Alto, California: Consulting Psychologists Press.

Swinburn, B., Egger, G., \& Raza, F. (1999). Dissecting obesogenic environments: The development and application of a framework for identifying and prioritizing environmental interventions for obesity. Preventive Medicine, 29(6), 563-570. https:// doi.org/10.1006/pmed.1999.0585.
Van Gucht, D., Vansteenwegen, D., Van den Bergh, O., \& Beckers, T. (2008). Conditioned craving cues elicit an automatic approach tendency. Behaviour Research and Therapy, 46(10), 1160-1169. https://doi.org/10.1016/j.brat.2008.05.010.

Vervoort, E., Vervliet, B., Bennett, M., \& Baeyens, F. (2014). Generalization of human fear acquisition and extinction within a novel arbitrary stimulus category. PLoS One, 9(5), e96569. https://doi.org/10.1371/journal.pone.0096569.

Vriends, N., Michael, T., Blechert, J., Meyer, A. H., Margraf, J., \& Wilhelm, F. H. (2011). The influence of state anxiety on the acquisition and extinction of fear. Journal of Behavior Therapy and Experimental Psychiatry, 42(1), 46-53. https://doi.org/10.1016/ J.JBTEP. 2010.09.001.

Wardle, M. C., Lopez-Gamundi, P., \& Flagel, S. B. (2018). Measuring appetitive conditioned responses in humans. Physiology \& Behavior, 188, 140-150. https://doi.org/10. 1016/J.PHYSBEH.2018.02.004.

Watson, P., Wiers, R. W., Hommel, B., Gerdes, V. E., \& de Wit, S. (2017). Stimulus control over action for food in obese versus healthy-weight individuals. Frontiers in Psychology, 8, 580.

Wilfley, D. E., Schwartz, M. B., Spurrell, E. B., \& Fairburn, C. G. (1997). Assessing the specific psychopathology of binge eating disorder patients: Interview or self-report? Behaviour Research and Therapy, 35(12), 1151-1159.

Winkelmann, T., Grimm, O., Pohlack, S. T., Nees, F., Cacciaglia, R., Dinu-Biringer, R., et al. (2016). Brain morphology correlates of interindividual differences in conditioned fear acquisition and extinction learning. Brain Structure and Function, 221(4), 1927-1937. https://doi.org/10.1007/s00429-015-1013-Z.

Wong, A. H. K., \& Lovibond, P. F. (2018). Excessive generalisation of conditioned fear in trait anxious individuals under ambiguity. Behaviour Research and Therapy, 107, 53-63. https://doi.org/10.1016/J.BRAT.2018.05.012.

Zhang, Z., Manson, K. F., Schiller, D., \& Levy, I. (2014). Impaired associative learning with food rewards in obese women. Current Biology, 24(15), 1731-1736. https://doi. org/10.1016/j.cub.2014.05.075.

Ziauddeen, H., Farooqi, I. S., \& Fletcher, P. C. (2012). Obesity and the brain: How convincing is the addiction model? Nature Reviews Neuroscience, 13(4), 279-286. https:// doi.org/10.1038/nrn3212. 